Body \& Society 2001 7(1):121-125

DOI: $10.1177 / 1357034 X 01007001008$

The online version of this article can be found at:

http://bod.sagepub.com/content/7/1/121

\title{
World on a Platter?: Consuming Geographies and the Place of Food in Society
}

Rebecca Kennison

Consuming Geographies: We Are Where We Eat

David Bell and Gill Valentine

London: Routledge, 1997, pp. 236, ISBN 0-415-13768-3, £15.99 (pbk); pp. 256, ISBN 0-415-

13767-5, £55.00 (hbk)

The day I got my copy of David Bell and Gill Valentine's Consuming Geographies: We Are Where We Eat, I also received my monthly issue of Gourmet magazine. After reading what Bell and Valentine have to say about food and its connection with the body, home, community, city, region, nation, and world, I find my view of Gourmet - as well as of the contents of my refrigerator and larder, of my local supermarket and of the restaurants I frequent - completely changed.

Consuming Geographies is a heady brew of sociology and cultural geography laid out in a thoughtful, well-written, well-organized, witty manner; unfortunately, for all the richness of the offering, the book also seems to have bitten off just a little bit more than it can comfortably chew.

This is not for lack of trying to keep the bites a manageable size. The book neatly lays the table with the place-settings of body, home, community, city, region, nation, and globe and continually draws connections between the chapters that show that these are very much the ingredients for creating a culinary dish of self-construction. Well over half the book is devoted to the body ( 36 pages), home (32 pages), community (30 pages), and city (26 pages) - in other words, to localized spaces - with less emphasis placed on region (18 pages), nation (22 pages), and globe (23 pages), despite the fact that most people would think of food in primarily those regional, national, or global ways (Southern cooking, Japanese food, the ubiquitous McDonald's and Coca-Cola). Of course, none of these spaces are as tidily distinct as the chapter titles would seem to imply, something Bell and Valentine readily admit and enjoy playing with as they fold one ingredient into another, especially in the final chapters on city, region, nation, and the global, where they question the very constructs of these terms, just as they do those of home and community - and finally suggest that the reader be the final arbiter of what these mean, thus bringing the discourse back to the level of the body, perhaps justifiably, since that seems to be the only space that remains stable in this construct, as the actual point of contact with food.

Unifying themes marbled throughout the text are those of food and gender, food and sex, food and class, food and race (the discussion of colonial influence, especially Indian influence, on British food consumption - a sort of culinary "Empire Strikes Back" - is 
especially good), and food and age, always with an emphasis on food as inclusion and as exclusion that connects this study well with Bell and Valentine's past work on sexualities and Valentine's recent work on children. This is especially true of the discussion of food and sex in the form of "gastroporn," which is pervasive in ads, books, movies - Isabel Allende's newest book, Aphrodite: A Memoir of the Senses, comes to mind, for example, as well as numerous recent movies such as Like Water for Chocolate (which Bell and Valentine mention), the artichoke scene in Antonia's Line (surely one of the sexiest scenes ever filmed), Babette's Feast, Eat Drink Man Woman, The Wedding Banquet, Strawberry and Chocolate, and Soul Food.

Once you're sensitized to seeing gastroporn, you notice it everywhere. For example, in addition to the Taco Bell ads currently running on American television that feature a Chihuahua lusting after fast-food Mexican cuisine, two other recent ads directly feed off the whole conceit. In one, for the Dunkin' Donuts chain, stereotypical construction workers on a very hot day are shown (in a non-stereotypical manner) ignoring gorgeous women in skimpy dresses walking down the street. Then the wolf whistles start - for a chubby middle-aged man who's carrying a tray of Dunkin' Donuts' iced coffee. "It's a thing of beauty," the voiceover says. In the other ad, two women are discussing men at a bar who seem to be ogling them. "They only have one thing on their mind," they agree. The camera zooms in on a Budweiser sitting between the women and then on one fellow handing the other a Bud. "Thanks," says the guy, "you read my mind."

This discourse on gastroporn, combined with a nicely nuanced discussion of food and gender roles sprinkled throughout the chapters, makes for a spicy consideration of food and sexuality. The discussions of food and class and of food and age are also interesting and thought-provoking.

Most striking is the argument that consumption can be reduced to the concept of "glocalization" (Robertson, 1995: 27) - the global as local, the local as global - a point made most clearly by the irony of the existence in the Midlands of an "authentic British base of balti cuisine" - a northern Pakistani dish. The point is made here and elsewhere that it is South Asian food that is now the British national cuisine - in other words, that there is no such thing as a "national" food. Similarly, on this side of the Atlantic, surprising as it may be initially to find chili called a Cincinnati staple (pp. 159-160) - my first thought was to wonder what San Antonians would say to that, since chili originated there and didn't "go national" until the turn of the century (Fussell, 1986: 45) - the point is equally strong: Cincinnati has made chili its own regional dish, one that has national and even international impact.

That "glocalization" has deep roots is evident in such mundane details as Safeway being cited as often by the British interviewees in the book as Sainsbury's or in the unavoidably irony found in the Staffordshire example that opens the chapter on regionalism that Staffordshire may indeed have chosen Pepsi in taste tests, a point of regional pride (at least in the advertiser's mind), but Pepsi is an American company.

As the examples above show, although the attempt is made to present a global smorgasbord, the book, with its emphasis on "glocalization," is determined to make the local focal and is therefore unabashedly Anglocentric, something that for the most part seems reasonable - both authors live and work in the UK, after all, and most of the book is focused on the geographies of body, home, community, city, region, and nation - but that can be intrusive for someone outside the country. (What, for example, is social class $A B$ ?) 
One instance of British cultural focus is the comment on p. 131 that eating outdoors is generally frowned upon. That may be true in England, but it is certainly not the case everywhere, where outdoor cafés and street vendors are part of everyday culinary life. Despite its British focus, the book still resonates with my experiences living and eating in a variety of spaces around the world - as it would for pretty much anyone reading it — but that is just one of the connections that I as the reader have to bring to the table myself. "We must always see the interconnections, which are much more numerous and complex than we can possibly show here," Bell and Valentine cajole us (p. 187), but I would have liked them to unpack those interconnections a bit more, instead of leaving it to the reader to flesh them out, much as I enjoyed doing that myself.

In fact, if I have a beef with the book, it would be that it is too short, that before I have the chance to sink my teeth into a concept and chew it over, that plate is removed and another appetizing morsel is put in its place. For example, in the chapter on home, I would have liked much more discussion on food in non-traditional "home situations" - living alone, living with roommates or housemates, living in a same-sex couple arrangement (which, although mentioned, is not explored, except in the sidebars featuring Kate), having visitors over for a meal (especially at holidays). I kept waiting for a discussion of entertaining at home with friends - but there is barely a mention of that activity, although it is one that forms a major part of my own social interactions (and I suspect in this I am not alone): casual dinners, formal dinners, birthday parties, potlucks, wedding receptions, all of which speak resonantly to me about ideas of private and public space and home versus community.

Similarly, there is almost no discussion of corner grocery stores in the section on community, with only short shrift given to them in the discussion on supermarkets. Yet when I lived in Germany several years ago, I had numerous conversations with friends concerning shopping at the neighborhood specialty shops (the bakery, the butcher's, the confectioner's, etc.) versus the local supermarket, which carried the disconcertingly English-language name (emphasizing its cosmopolitan nature, I suppose) Big (a subtitle for German speakers explained: "Ein großes Einkaufen"). Most of us shopped at Big, but we were embarrassed to run into each other there. The struggle between big chain supermarkets and small, locally owned corner markets or co-ops continues unabated even now - and not just in Germany - and would have seemed a fruitful topic for exploration.

On the regional level, there is also no discussion (except as it is mentioned in passing by one interviewee) of linguistic exclusion - an insider/outsider distinction based on what food is called. Pierre Bourdieu's (1991) point that the power to include and exclude resides in naming should not go unremarked. Here in Boston, for example, you need to know what a frappé (pronounced to rhyme with gap) and a grinder are, while an British friend of mine once confused a waitress at Logan Airport by asking for an orange squash - conjuring up in that woman's mind some sort of gourd, I suspect, rather than something to drink - and we won't even touch terms like biscuits or chips or corn that show that even English speakers don't speak the same language. Nevertheless, how one talks about food is as defining of space and one's place in it as how one eats one's chips or French fries.

Despite Consuming Geographies' focus on local and regional space (i.e., Britain), from time to time Bell and Valentine make forays into the eating habits of other cultures, particularly in their discussions of national and global food consumption, and it is therefore 
more than a bit disconcerting that no mention is made at all of that most nationalistic of American meals, Thanksgiving, a feast that would have provided a nice counterbalance to their discussion of an Australian cuisine that ignores aboriginal food. After all, few meals are more "native" in their origin (or more weighed down with colonialist baggage) than the staples of a traditional Thanksgiving dinner - turkey, cranberry sauce, mashed potatoes, succotash, pumpkin pie - all foods introduced by Native Americans to the colonists, who adopted the food and then tried to eliminate the people, a colonization not only reenacted but celebrated in almost every American home every year. Thanksgiving is the quintessential American holiday - more people travel "home" for that one meal than for any other celebration in the year, even Christmas - and it deserves to be examined, especially in light of the arguments Bell and Valentine have presented here for the connections between and among the body, home, community, city, region, and nation.

Finally, speaking of traveling, surprisingly this book never does; even in discussions of global consumption, there is no mention of the "moveable feast" - of food in cars (e.g., drive-through culture and what that says about private consumption in a public space), trains, planes (especially the conscientiously "national" cuisine offered by national airlines on international flights), or cruise ships (known for their constant offerings of mountains of food). A world on the move is still a world that eats - almost nonstop, it seems - and I would have liked to have seen some discussion, or at least a mention, of that.

At just over 200 pages, including the bibliography and index, this book is admirably lean - but I for one would have loved to see more meat on its bones, especially given that it is such an enjoyable read in both style and content. Even so, Consuming Geographies is a very important contribution, not least in providing food for thought that allows the reader to nibble at the edges of her own culinary nexus of body-global interaction, by becoming aware of that most basic of truth: we are what we eat - and, as Bell and Valentine have shown, where we eat as well. Now, where'd I put that copy of Gourmet?

\section{References}

Bourdieu, Pierre (1991) Language and Symbolic Power, ed. J. B. Thompson, trans. G. Raymond and M. Adamson. Cambridge, MA: Harvard University Press.

Fussell, Betty (1986) I Hear America Cooking. New York: Sifton-Viking. Robertson, Roland (1995) "Glocalisation: Time-Space and Homogeneity-Heterogeneity," pp. 25-44 in M. Featherstone, S. Lash, and R. Robertson (eds.) Global Modernities. London: Sage.

Rebecca Kennison is a journals senior production editor for Blackwell Publishers in Malden, Massachusetts. Her research interests include human geography, gender studies, and twentieth-century colonialist literature. 